\title{
The Effect of the Group Cognitive Behavior Therapy in a Nurse's Burnout and Intention to Resign
}

\author{
Takashi Ohue ${ }^{1}$, Michiko Moriyamaㄹ, Takashi Nakaya ${ }^{3}$ \\ ${ }^{1}$ Department of Nursing Science, Faculty of Health Science, Hyogo University, Kakogawa-Shi, Japan \\ ${ }^{2}$ Division of Nursing Science, Graduate School of Health Sciences, Hiroshima University, Hiroshima, Japan \\ ${ }^{3}$ Faculty of Health and Welfare, Prefectural University of Hiroshima, Hiroshima, Japan \\ Email: ohue@hyogo-dai.ac.jp, morimich@hiroshima-u.ac.jp, nakaya@pu-hiroshima.ac.jp
}

Received 26 August 2015; accepted 27 September 2015; published 30 September 2015

Copyright (C) 2015 by authors and Scientific Research Publishing Inc.

This work is licensed under the Creative Commons Attribution International License (CC BY). http://creativecommons.org/licenses/by/4.0/

(c) (i) Open Access

\begin{abstract}
Purpose: The purpose of the present study was to decrease burnout and intention to resign by practicing cognitive behavioral approach to nurses of the 3 years nursing clinical experience. Methods: Nurses $(\mathrm{N}=180)$ who worked at acute-care hospitals and whose clinical experience was 3 years were requested. Nurses $(n=95$, male 5 , female 90$)$ who were able to do participation at all the sessions were objects. The program was created and carried out for a nurse's burnout with reference to cognitive behavior therapy. Evaluation of intervention was asked to complete a questionnaire that measured burnout (MBI), job stressors (NJSS), automatic thoughts (the shorter version of Japanese version ATQ-R), Irrational Belief Test for Nurses (IBTN), coping measure and whether or not they had an intention to resign. Measurement was performed 3 times of a baseline, after the end of session and follow-up. Analysis of covariance which adjusted the baseline level was performed. Result: According to the results, "helplessness", "positive thinking" and "personal accomplishment" were significant $(p<0.01)$. According to the results of Friedman test, significant difference was observed in "emotional exhaustion" in the group with low degree of irrational belief $(p<0.10)$ and in the group with high degree $(p<0.05)$. With regard to the intention to leave the job, "wants to continue working as a nurse" was significant in the group in 3 months after intervention $(p<0.05)$. Conclusion: It is suggested that cognitive behavioral approach appears to be effective for reducing nurse's burnout or intention to resign in nurses of the 3 years nursing clinical experience.
\end{abstract}

\section{Keywords}

Cognitive Behavior Therapy, Nurse, Burnout, Intention to Resign 


\section{Introduction}

The turnover rate in nurses was 10.9\% in 2012 in Japan. However, the tendency for the turnover rate to exceed the national average continues in the urban areas [1]. It has been indicated that their long-term absence or separation from job is associated with burnout in addition to the excessive amount of work [2] [3]. Burnout has been defined as "a syndrome of mental/physical fatigue and emotional exhaustion that occurs among individuals who work with people in a certain capacity over prolonged periods of time, and also self-abasement, distaste for work and lack of compassion for others" [4]. It has been suggested that approaches to reduce burnout could include intervention at the organization level such as coordination of the amount of tasks [5] or at the personal level such as reinforcement of cognitive management [6] [7]. With regard to depression which is considered as an advanced stage of burnout [8], cognitive therapies for depression suggested by Beck [9] and Ellis [10] have been performed intensively in the field of psychology not only for nurses but also for people in general and proven effective. It can be assumed that onset of burnout may involve irrational beliefs as suggested by Ellis [10] or cognitive factors such as automatic thoughts as suggested by Beck [9], considering that onset of depression is induced by cognitive distortion [11], that burnout can affect depression, and that some people may experience burnout while others may not in the same working environment. Ellis conceptualized the belief system represented by the word "must," which is related to depression, and an unfounded, but absolute and ideological concept, defined as “irrational belief." [10] The automatic thoughts indicate arousal of particular distorted thoughts which are different from objective facts when a person with the irrational belief as a scheme (cognitive style) faces a stressful event in a daily situation; both the scheme and the automatic thoughts are conceptualized as cognitive distortion [11]. The irrational belief contains occupational characteristic [12], and it is known that nurses also have particular irrational beliefs [13]. It is not clear whether a person with particular characteristics becomes a nurse or the nursing job itself influences the person to have a particular thought. However, it has been revealed that they have remarkable characteristics of feelings such as "dependence”, "problem avoidance” and "helplessness” out of "patient belief”, “self-expectation”, "problem avoidance”, "self-control”, “logical criticism”, "helplessness" and "dependence” and that these have been associated with burnout [13]. Then, it is also suggested that cognitive behavioral therapy may be effective for reduction of burnout or Intention to leave the job due to cognitive distortion in nurses [14]. Taking these findings into consideration, it was thought that the cognitive behavioral therapy, which has been used to treat depression, can be applied for nurses to prevent their burnout. There is no study available yet which has proven effectiveness of this approach. Therefore, if effectiveness of this intervention is verified, the process that the irrational belief, as a factor causing burnout in nurses, induces automatic thoughts and results in burnout will be also rationalized. At the same time, it will be possible to provide a systemic approach, such as improvement of working environment for nurses, as well as an approach for individual factors with the cognitive behavioral therapy, which is highly cost effective. It is thought that these approaches will make the preventive measure against job separation in nurses more stratified.

Consideration of an intervention model and development of “a burnout prevention program for nurses".

The thing that how recognition works after receiving stimulation (stressor), results in burnout and performs a covariance structure analysis is investigated. As a result, it was found that there was a path following "stressor" => "irrational belief" => "negative automatic thoughts", "positive automatic thoughts"=> "burnout" and a path which directly connected "stressor" and "burnout”. The goodness-of-fit of the structural model which combined these two paths appeared satisfactory [14] (Figure 1). As changes in cognition of nurses alone seemed inadequate to bring a result, as a cognitive behavioral therapy combining manipulation on nurses' cognition (modifying irrational beliefs) with behavioral therapy (acquisition of coping skills) to reduce the direct effects was attempted to make a compound intervention (Figure 1). According to Wright et al., establishment of coping skills is one of the behavioral techniques to be added to the cognitive techniques [15], and Kubo indicates that there is coping between stressor and burnout [16]. We also included the problem-solving technique to acquire the coping skills [17].

\subsection{Program Structure}

According to the results of a study conducted by Ohue et al. [14], followings should be considered when creating a program: 1) provision of information on relationship between stressor and burnout, 2) trainings to reduce burnout by changing cognition, and 3) trainings for coping, which seems to be effective for burnout (trainings for the problem solving techniques). Correct information or knowledge should be provided (lectured) in psy- 


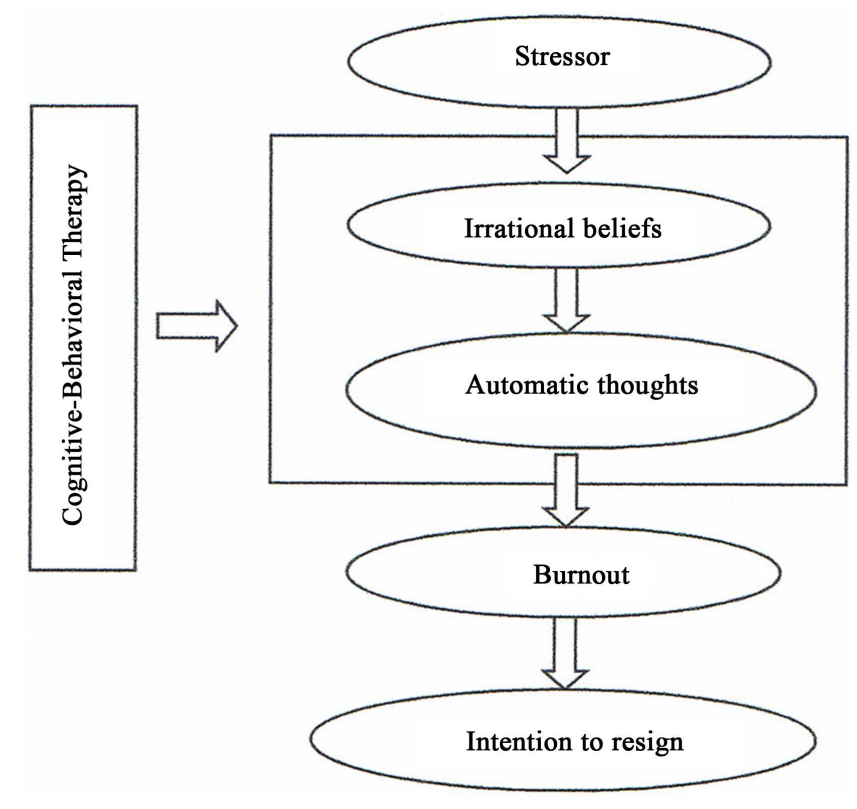

Figure 1. Intervention construction drawing of cognitive behavior therapy program.

chological education since provision of correct knowledge regarding stress or burnout to nurses can make them recognize their stress which they had never been aware of and knowing strategies against stress or burnout such as recognition change or a problem resolving technique is thought to reduce stress or burnout. Moreover, psychological education should not just end up by providing information [18]; this program should not only provide information but also should create group dynamic to let them share information or the same problems. It is also necessary to make psychological education and group works generalized (carried out in actual situations) in daily nursing tasks. In the cognitive behavioral therapy, homework (assignments to be completed at home) may be used for generalization [19]. Therefore, homework assignment is given in this program as well. In order to reinforce these educations, I developed a workbook with which an individual can earn through working on assignments regarding recognition change or problem resolution. For homework, a thought recording chart to which an individual can write down automatic thoughts and feelings at that time was created and used, as well as arguments against the thoughts everyday whenever a stressful event occurs.

Hence, the structure of the program as a package of "psychoeducation intervention + groupwork + homework" was designed. The format to provide the contents was a combination of a lecture-style psychological education to teach knowledge, group work to apply the newly learned knowledge, and homework to acquire the new recognition. This package was conducted for a total of 3 times; once a week for about 60 minutes per each time because of clinical convenience (Table 1).

\subsection{An Objective of This Study}

The objective of this study is to investigate effectiveness of a burnout prevention program using the cognitive behavioral therapy for nurses, which consists of correction of cognitive factors (irrational belief and automatic thoughts) and acquisition of coping behaviors.

\section{Methods}

\section{1) Participants}

According to the results that burnout risk is high among nurses with 3 years of clinical experiences, 3 shiftwork in hospitals [4] [14], to include nurses in their third year of clinical practice, working at an acute hospital in this study was designed. The facilities subjected in this study were 5 hospitals which were randomly selected from all acute hospitals in Kansai area where many newly graduated nurses work, and agreed to cooperate in this study. We recruited from these hospitals a total of 180 nurses in their third year of the clinical practice. 
Table 1. A summary of a cognitive behavioral therapy program for burnout prevention.

\begin{tabular}{|c|c|c|c|}
\hline & Psychoeducation & Groupwork & Homework \\
\hline First time & $\begin{array}{l}\text { Psychoeducation } \\
\text { regarding stress, burnout } \\
\text { and related factors } \\
\text { using a leaflet. }\end{array}$ & $\begin{array}{l}\text { Discuss problems, stressful matters, } \\
\text { and stress reactions. (Externalization of } \\
\text { the problems) A facilitator } \\
\text { summarizes each point and } \\
\text { clarifies the problems using a help sheet. }\end{array}$ & $\begin{array}{l}\text { Submit a workbook which } \\
\text { contains today's review } \\
\text { and a thought recording } \\
\text { table (events and feelings) } \\
\text { once a week. }\end{array}$ \\
\hline Second time & $\begin{array}{l}\text { Psychoeducation using a leaflet, which } \\
\text { helps participants to learn that there } \\
\text { is a way of thinking (thoughts) between } \\
\text { stress and burnout and that feelings } \\
\text { can change when the way of thinking } \\
\text { changes even with the same event. }\end{array}$ & $\begin{array}{l}\text { Argue against ideas under } \\
\text { a stressful situation } \\
\text { using a help sheet. }\end{array}$ & $\begin{array}{l}\text { Submit a workbook which } \\
\text { contains today's review } \\
\text { and a thought recording } \\
\text { table (events, feelings, } \\
\text { automatic thoughts and } \\
\text { arguments) once a week. }\end{array}$ \\
\hline Third time & $\begin{array}{c}\text { Psychoeducation about } \\
\text { coping and problem solving } \\
\text { techniques using a workbook. }\end{array}$ & $\begin{array}{l}\text { Do activities with discussion } \\
\text { in a group, based on five } \\
\text { processes of the problem resolving } \\
\text { technique using a help sheet. }\end{array}$ & \\
\hline
\end{tabular}

2) Evaluation indicators and points

Burnout and intention to leave the job were determined to be the primary endpoints in this study. Then, irrational belief, automatic thoughts, and coping were determined to be the secondary endpoints, which affect the primary endpoints.

a) Burnout: Maslach Burnout Inventory (MBI) was used [20]. This is a scale introduced by Maslach et al. [4] and modified by Tao et al. [21], consisting of 3 factors: “emotional exhaustion”, “depersonalization” and "personal accomplishment”. Its reliability and validity have been confirmed. It contains a total of 17 items evaluated by five levels from "always present" to "absent”. The higher the scores for "emotional exhaustion" and "depersonalization", and the lower the scores for "personal accomplishment”, the more likely the participants develop burnout.

b) Intention to leave the job: According to the categories introduced by Tsuchie et al. [3], presence or absence of Intention to leave the job including "Wants to quit working as a nurse", "wants to switch hospitals or departments" and "wants to continue working as a nurse” are evaluated by 5 levels from "always present” to "absent”. The higher the scores, the stronger the participants' will.

c) Irrational belief of nurses: The scale introduced by Ohue et al. was used [13]. Reliability and validity have been confirmed. The scale consists of 7 factors: "Patient belief”, "Self-expectation”, "problem avoidance”, "self-control”, "logical criticism”, "helplessness” and “dependence” with 28 items. Evaluations were made in 5 levels from "totally agree" to "do not agree at all”; the higher the scores, the more intensively the participants had irrational belief. Only the items of the factors "problem avoidance”, "helplessness" and "dependence”, which had been associated with burnout according to the results of the study by Ohue et al. [14], were used.

d) Automatic thoughts: "the ATQ shorter form" introduced by Ohue et al. was used [22]. Reliability and validity had been confirmed. This scale consists of “Automatic Thoughts Questionnaire-Revised” (hereinafter, ATQ-R) introduced by Kodama et al. [23] with a total of 18 items: 6 items of "negative evaluation of the future", 6 items of "self-blame”, and 6 items "positive thinking”. Evaluations were made in 5 levels from "totally agree” to "not agree at all", indicating that the higher the scores, the more intensively the participants have the subscale automatic thoughts.

e) Coping: "the coping scale” introduced by Ozeki was used for evaluations of coping [24]. This scale is a simplified version of a coping scale introduced by Sakata [25], consisting of a total of 14 items: 5 items of "problem-focused coping”, 3 items of “emotion-focused coping”, and 6 items of "escape-avoidance coping”. Reliability and validity had been confirmed. Evaluations were made in 4 levels from "do not at all” to "always do”, and the scores for 3 subscales could be obtained. The higher the scores, the more the participants had coping behaviors".

f) Measurement of stressors: Higashiguchi's Nursing Job Stressor Scale (NJSS) was used [26]. NJSS consists of 33 questions that describe potential stressful situations for nurses divided into the following seven subscales: "conflict with other nursing staff," “nursing role conflict," "conflict with physicians/autonomy” "dealing with death and dying," "qualitative workload," “quantitative workload,” and "conflict with patients.” The higher the score is, the greater the burden of the stressor is. 
Only the items of "conflict with other nursing staff," "nursing nursing role conflict," "qualitative workload," "quantitative workload," and "conflict with patients were used.

a)-f) were measured before intervention, after intervention and 3 months later. For (6), evaluations were made only before intervention.

3) Recruitment and procedure

Third year nurses who agreed to attend were recruited at hospital seminars, and their consent forms were obtained. They were placed into a group of five people, which was the size most suitable for discussions, and the program was conducted by the researcher, who was also a lecturer and facilitator. They were asked to fill out the evaluation indicators at the start of intervention, at the end of the session, and 3 months after completion of the session, totally 3 times.

4) Study design and methods of analysis

Considering that everyone can have irrational beliefs and that the degree of the beliefs affects burnout [14], the same program was applied to all participants without setting a control group in this study. In analysis, participants were classified into the groups with low degree of "irrational belief" and high degree of "irrational belief" using the median value. Then, a comparative study was performed without using a control group to assess which group showed more effects. Classification into the groups with low and high degree of "irrational belief" took place after completion of intervention. The study was conducted between April 2012 and March 2014.

The following procedures were taken in analyses of evaluation indicators.

a) Firstly, the median of the scores for irrational belief was calculated, and the participants were classified into the low and high degree of irrational belief in order to evaluate the effects of burnout prevention program with a recognition change.

b) t-test was performed in order to compare the group with high degree of irrational belief and the low degree of irrational belief at the baseline.

c) After completion of each subscale session, analysis of covariance was performed using data obtained at 3 months after completion of the session as dependent variable, the groups with high and low degree of irrational belief as independent variable, and the baseline before intervention as covariance. When comparing the groups with high and low degrees of irrational belief at the timing of intervention, the baseline values could become extraneous variable and affect the values obtained after intervention or at 3 months after completion of the intervention. Therefore, analysis of covariance was performed in order to avoid statistics confounding.

d) Friedman test was performed on comparisons over time between groups with low and high degrees of irrational belief. In addition, if a significant difference was observed, the scores obtained at each time of intervention were compared using Wilcoxon signed rank test. Statistical significance was set at $P<0.10$.

5) Ethical considerations

The protocol of this study was approved by the Hyogo University Ethics Committee. Written agreement of participation was received prior to this intervention from Directors of Nursing at the hospitals. Then, I provided explanations regarding this study with a written form to the nurses who attended the seminars, and the study was conducted only in the nurses who had submitted the consent. For the nurses, it was mentioned in a written form that the participants could make a free-will choice on participation in this study so they can disagree to participate or discontinue participation in this study without having any disadvantages and that data would not be used outside this study. It was also explained that the data obtained were processed statistically using code numbers.

\section{Results}

1) Participation in the study

Informed consent for participation was obtained from 126 nurses (Response rate 70\%). During the intervention 21 more nurses dropped out due to working time conflict, consequently 105 nurses completed the program. Furthermore, 10 nurses dropped out during the follow-up period. Therefore, 95 nurses ( 5 male, 90 female) were analyzed (Figure 2).

2) Basic characteristics

The participants included 5 male and 90 females with the mean age of $25.06 \pm 4.18$ years old. With regard to marital status, 5 participants were married and 90 were single. The final educational backgrounds were nursing schools in 70 participants, universities in 15, and advanced course in 10. Their current departments were 14 participants in outpatient clinics, 4 in operation rooms, 10 in ICU, 68 in wards. Since difference was not observed 


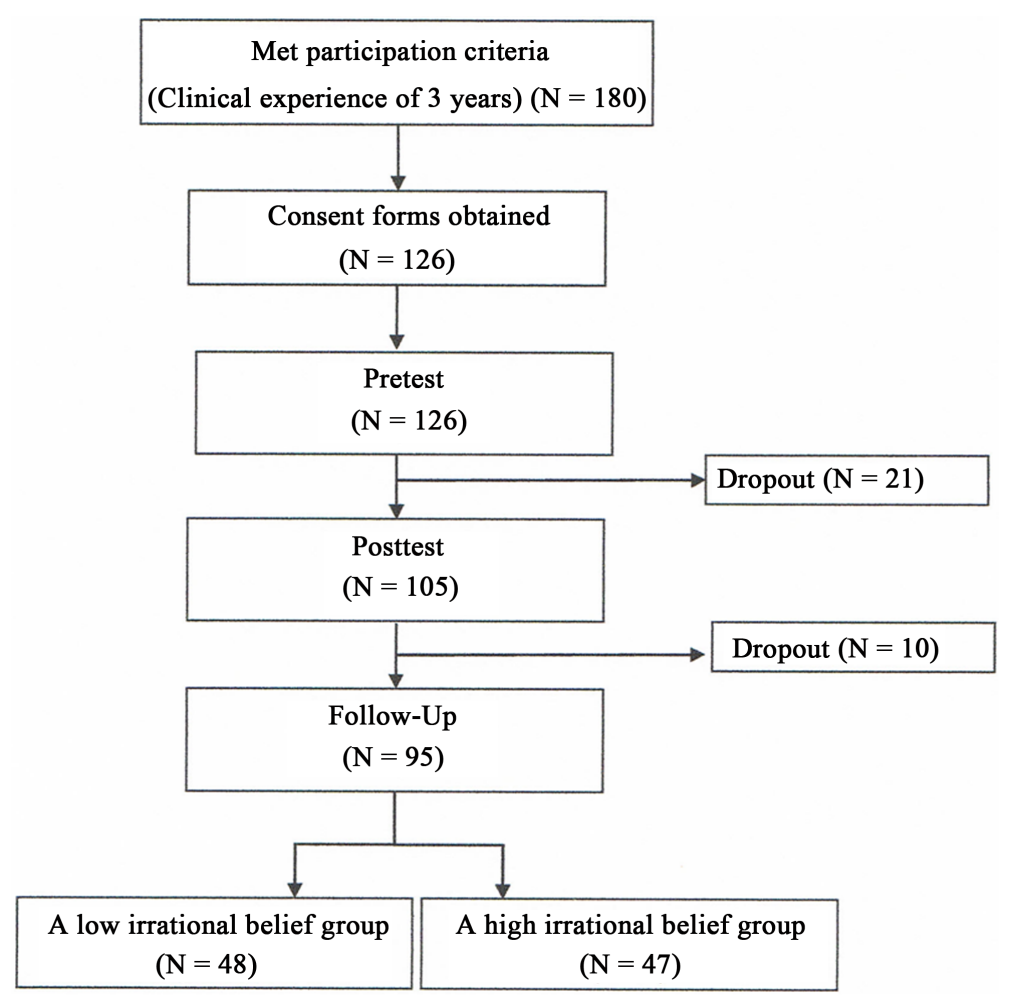

Figure 2. A participant's circumstances.

between female and male nurses in irrational beliefs of nurses [14], one male subject was included to the analysis.

3) Baseline comparisons between the groups with high and low degrees of irrational beliefs

Using the median value, 36, of the scores for irrational belief, 95 participants were classified into the groups with low $(\mathrm{N}=48)$ and high $(\mathrm{N}=47)$ scores. In these 2 groups, t-test was performed in order to make baseline comparisons regarding 5 subscales of NJSS to measure stressors, 3 subscales of IBTN to measure irrational beliefs, 2 subscales of ATQ-R shorter form to measure automatic thoughts, 3 subscales of the coping scale to measure coping, 3 subscales of MBI to measure burnout, and 3 categories for the Intention to leave the job (Table 2).

As a result, for irrational beliefs, significant differences were observed in the total score $(p<0.001)$, problem avoidance $(p<0.01)$ and dependence $(p<0.05)$; the scores were higher in the group with high degree of irrational belief compared to the group with low degree. With ATQ-R, significant differences were observed in Negative evaluation of the future $(p<0.05)$ and Self-blame $(p<0.05)$, indicating that the scores for Negative evaluation of the future and Self-blame were higher in the group with high degree of irrational belief than in the group with low degree; That is, participants with high degree of irrational beliefs show higher negative evaluation of the future and self-blame. In the coping scale, no significant difference was observed; That is, there was no difference in coping in association with high or low degree of irrational beliefs. A significant difference was observed in emotional exhaustion $(p<0.05$ ) with MBI, suggesting that emotional exhaustion is more prominent in the group with high degree of irrational belief compared to the group with low degree. With regard to the intention to leave the job, a significant difference was observed in "desire to change the hospital/department" ( $p<$ 0.05 ), indicating that the group with high degree of irrational beliefs showed a higher rate in willingness to change the hospital or department compared to the low degree group. On the other hand, no significant difference was observed in all subscales with NJSS; perception of stressors was not associated with high or low degree of irrational belief or automatic thoughts.

4) Effects of the program

Analysis of covariance was performed by setting after completion of intervention and 3 months after the completion of intervention as dependent variables, and the groups with high and low degree of irrational beliefs 
Table 2. Comparison of baseline.

\begin{tabular}{|c|c|c|c|c|c|}
\hline \multirow[b]{2}{*}{ NJSS } & \multicolumn{2}{|c|}{ A low irrational belief group $(N=48)$} & \multicolumn{3}{|c|}{ A high irrational belief group $(N=47)$} \\
\hline & M & SD & M & SD & $t$ \\
\hline The total strain & 70.11 & 10.98 & 73.00 & 9.91 & 0.57n.s. \\
\hline Conflict with other nursing staffs & 18.44 & 3.57 & 20.63 & 3.20 & 1.32n.s. \\
\hline Nursing role conflict & 14.22 & 3.19 & 12.88 & 3.60 & 0.82n.s. \\
\hline Qualitative work load & 15.22 & 2.86 & 16.13 & 2.70 & 0.67n.s. \\
\hline Quantitative work load & 16.67 & 2.69 & 18.00 & 1.60 & 1.22n.s. \\
\hline Conflict with patients & 5.56 & 1.24 & 5.38 & 2.07 & 0.02n.s. \\
\hline \multicolumn{6}{|l|}{ IBTN } \\
\hline The total of an irrational belief & 35.22 & 1.86 & 42.50 & 4.21 & $4.71^{* * * *}$ \\
\hline Problem avoidance & 9.78 & 2.54 & 13.13 & 3.31 & $2.35^{* *}$ \\
\hline Helplessness & 12.00 & 1.87 & 13.88 & 2.90 & 1.60n.s. \\
\hline Dependence & 13.44 & 1.59 & 15.50 & 2.14 & $2.27^{*}$ \\
\hline \multicolumn{6}{|l|}{ ATQ-R } \\
\hline Negative evaluation of the future & 12.44 & 4.48 & 17.50 & 5.37 & $2.12^{*}$ \\
\hline Self-blame & 16.22 & 3.60 & 19.88 & 3.00 & $2.26^{*}$ \\
\hline Positive thinking & 20.33 & 2.00 & 17.88 & 3.52 & $1.80 ?$ \\
\hline \multicolumn{6}{|l|}{ Coping } \\
\hline Problem-focused Coping & 7.00 & 2.45 & 8.13 & 2.47 & 0.94n.s. \\
\hline Emotion-focused coping & 6.11 & 2.03 & 5.50 & 2.62 & $0.54 \mathrm{n} . \mathrm{s}$. \\
\hline Escape-avoidance coping & 7.78 & 4.15 & 7.63 & 4.84 & 0.07n.s. \\
\hline \multicolumn{6}{|l|}{ MBI } \\
\hline Emotional exhaustion & 16.44 & 3.40 & 19.88 & 3.48 & $2.05^{*}$ \\
\hline Depersonalization & 12.56 & 3.81 & 15.38 & 6.59 & 1.10n.s. \\
\hline Personal accomplishment & 15.33 & 4.85 & 15.00 & 4.72 & $0.14 n . s$. \\
\hline \multicolumn{6}{|l|}{ Intention to leave the job } \\
\hline Wants to quit working as a nurse & 2.44 & 1.13 & 2.88 & 1.73 & 0.62n.s. \\
\hline Wants to switch hospitals or departments & 2.11 & 0.78 & 3.38 & 1.30 & $2.46^{*}$ \\
\hline Wants to continue working as a nurse & 3.67 & 1.32 & 3.25 & 1.49 & 0.61n.s. \\
\hline
\end{tabular}

?: $p<0.10^{*}: p<0.05 ;{ }^{* *}: p<0.01 ;{ }^{* * *}: p<0.001$. n.s.: non significant.

as independent variables, and the scores before starting intervention as covariance (Table 3). The groups with high and low degree of irrational belief were compared by Friedman test according to the timing of intervention [before intervention (pretest), after the completion of intervention (posttest), and 3 months after the completion of intervention (follow-up)]. For items with which significant differences were observed, multiple comparisons were performed with Wilcoxon signed rank test (Table 4).

a) Primary endpoints: changes in irrational belief, automatic thoughts and coping in groups with high and low degrees of "irrational belief"

According to the results, the primary effect of "helplessness" was significant $(p<0.10)$ in the group with ir- 
Table 3. Result of covariance analysis which made group independent variable and made baseline covariance.

\begin{tabular}{|c|c|c|c|c|c|c|c|c|c|c|}
\hline & \multicolumn{4}{|c|}{ Posttest } & \multicolumn{5}{|c|}{ Follow-Up } & \multirow[b]{3}{*}{$\begin{array}{l}\text { Main } \\
\text { effect }\end{array}$} \\
\hline & \multicolumn{2}{|c|}{$\begin{array}{l}\text { A high irrational } \\
\text { belief group }\end{array}$} & \multicolumn{2}{|c|}{$\begin{array}{l}\text { A low irrational } \\
\text { belief group }\end{array}$} & \multirow[b]{2}{*}{$\begin{array}{l}\text { Main } \\
\text { effect }\end{array}$} & \multicolumn{2}{|c|}{$\begin{array}{l}\text { A high irrational } \\
\text { belief group }\end{array}$} & \multicolumn{2}{|c|}{$\begin{array}{l}\text { A low irrational } \\
\text { belief group }\end{array}$} & \\
\hline & $\begin{array}{l}\text { Estimated } \\
\text { average }\end{array}$ & SE & $\begin{array}{l}\text { Estimated } \\
\text { average }\end{array}$ & SE & & $\begin{array}{c}\text { Estimated } \\
\text { average }\end{array}$ & SE & $\begin{array}{c}\text { Estimated } \\
\text { average }\end{array}$ & SE & \\
\hline \multicolumn{11}{|l|}{ IBTN } \\
\hline $\begin{array}{l}\text { The total of an } \\
\text { irrational belief }\end{array}$ & 38.27 & 2.40 & 34.31 & 2.20 & 1.04n.s. & 37.02 & 2.67 & 37.43 & 2.46 & 0.01n.s. \\
\hline Problem avoidance & 12.50 & 1.00 & 10.88 & 0.94 & 1.21n.s. & 11.29 & 1.02 & 11.52 & 0.95 & 0.02n.s. \\
\hline Helplessness & 11.71 & 0.73 & 9.92 & 0.68 & $3.00^{\#}$ & 11.48 & 0.80 & 11.35 & 0.75 & $0.02 \mathrm{n} . \mathrm{s}$. \\
\hline Dependence & 13.22 & 1.02 & 13.91 & 0.95 & $0.21 \mathrm{n} . \mathrm{s}$. & 14.01 & 0.83 & 13.77 & 0.78 & $0.04 \mathrm{n} . \mathrm{s}$. \\
\hline \multicolumn{11}{|l|}{ ATQ-R } \\
\hline $\begin{array}{l}\text { Negative evaluation } \\
\text { of the future }\end{array}$ & 14.13 & 1.41 & 12.78 & 1.31 & 0.44 n.s. & 14.42 & 1.55 & 14.85 & 1.45 & 0.04n.s. \\
\hline Self-blame & 18.70 & 1.38 & 16.16 & 1.29 & 1.58n.s. & 18.10 & 1.02 & 18.47 & 0.96 & 0.06n.s. \\
\hline Positive thinking & 20.99 & 0.77 & 17.79 & 0.72 & $8.45^{* *}$ & 22.19 & 1.06 & 18.72 & 1.00 & $5.17^{*}$ \\
\hline \multicolumn{11}{|l|}{ Coping } \\
\hline Problem-focused Coping & 8.87 & 1.10 & 7.34 & 1.03 & 1.00n.s. & 6.98 & 1.02 & 7.79 & 0.96 & $0.32 \mathrm{n} . \mathrm{s}$. \\
\hline Emotion-focused coping & 5.69 & 0.52 & 6.50 & 0.49 & 1.23n.s. & 5.66 & 0.80 & 5.97 & 0.76 & 0.08n.s. \\
\hline Escape-avoidance coping & 9.78 & 1.13 & 10.09 & 1.06 & $0.04 \mathrm{n} . \mathrm{s}$. & 9.67 & 0.96 & 9.52 & 0.91 & 0.01n.s. \\
\hline \multicolumn{11}{|l|}{ MBI } \\
\hline Emotional exhaustion & 16.93 & 0.81 & 18.51 & 0.76 & 1.78n.s. & 15.27 & 0.92 & 15.98 & 0.87 & $0.28 \mathrm{n} . \mathrm{s}$. \\
\hline Depersonalization & 14.26 & 1.31 & 12.78 & 1.24 & $0.35 n . s$. & 12.44 & 1.19 & 12.95 & 1.12 & $0.24 n . s$. \\
\hline Personal accomplishment & 15.41 & 1.10 & 15.74 & 1.04 & 0.05n.s. & 17.89 & 0.74 & 14.88 & 0.70 & $8.67^{* *}$ \\
\hline \multicolumn{11}{|l|}{ Intention to leave the job } \\
\hline $\begin{array}{c}\text { Wants to quit } \\
\text { working as a nurse }\end{array}$ & 2.29 & 0.27 & 1.97 & 0.26 & 0.73n.s. & 1.31 & 0.25 & 2.06 & 0.24 & $4.68^{*}$ \\
\hline $\begin{array}{l}\text { Wants to switch hospitals } \\
\text { or departments }\end{array}$ & 2.74 & 0.48 & 2.68 & 0.45 & 0.01n.s. & 2.20 & 0.34 & 2.27 & 0.32 & $0.02 \mathrm{n} . \mathrm{s}$. \\
\hline $\begin{array}{l}\text { Wants to continue } \\
\text { working as a nurse }\end{array}$ & 3.90 & 0.28 & 3.54 & 0.26 & 0.87n.s. & 4.16 & 0.29 & 3.53 & 0.27 & 2.54n.s. \\
\hline
\end{tabular}

Adjusted the value of the baseline: ${ }^{*}: p<0.10 ;{ }^{*}: p<0.05 ;{ }^{* *}: p<0.01$ n.s.: non significant.

Table 4. Irrational belief low group and high group, and intervention point of each subscale (Friedman test).

\begin{tabular}{|c|c|c|c|c|c|c|c|c|c|c|c|c|}
\hline & \multicolumn{6}{|c|}{ A low irrational belief group $(\mathrm{N}=48)$} & \multicolumn{6}{|c|}{ A high irrational belief group $(N=47)$} \\
\hline & \multicolumn{2}{|c|}{ Pretest } & \multicolumn{2}{|c|}{ Posttest } & \multicolumn{2}{|c|}{ Follow-Up } & \multirow{2}{*}{$\begin{array}{c}\text { Pretest } \\
\text { M }\end{array}$} & \multicolumn{3}{|c|}{ Posttest } & \multicolumn{2}{|c|}{ Follow-Up } \\
\hline & $\mathbf{M}$ & SD & $\mathbf{M}$ & SD & $\mathbf{M}$ & SD & & SD & $\mathbf{M}$ & SD & $\mathbf{M}$ & SD \\
\hline IBTN & & & & & & & & & & & & \\
\hline $\begin{array}{l}\text { The total of an } \\
\text { irrational belief }\end{array}$ & 35.22 & 1.86 & 33.67 & 4.09 & 35.78 & $6.59 \mathrm{n} . \mathrm{s}$ & 42.50 & 4.21 & 39.00 & 5.76 & 38.88 & $4.42 \mathrm{n} . \mathrm{s}$ \\
\hline Problem avoidance & 9.78 & 2.54 & 10.44 & 2.24 & 10.56 & $2.88 \mathrm{n} . \mathrm{s}$ & 13.13 & 3.31 & 13.00 & 3.02 & 12.38 & $3.38 n . s$ \\
\hline Helplessness & 12.00 & 1.87 & 9.56 & 1.88 & 10.78 & $2.54^{*}$ & 13.88 & 2.90 & 12.13 & 2.42 & 12.13 & $2.70^{\#}$ \\
\hline Dependence & 13.44 & 1.59 & 13.67 & 2.35 & 13.44 & 2.46n.s & 15.50 & 2.14 & 13.50 & 2.88 & 14.38 & $1.85 \mathrm{n} . \mathrm{s}$ \\
\hline
\end{tabular}




\section{Continued}

\begin{tabular}{|c|c|c|c|c|c|c|c|c|c|c|c|c|}
\hline ATQ-R & & & & & & & & & & & & \\
\hline $\begin{array}{l}\text { Negative evaluation } \\
\text { of the future }\end{array}$ & 12.44 & 4.48 & 11.56 & 4.36 & 13.56 & 4.56n.s & 17.50 & 5.37 & 15.50 & 4.38 & 15.88 & $5.00 \mathrm{n} . \mathrm{s}$ \\
\hline Self-blame & 16.22 & 3.60 & 16.11 & 3.76 & 17.33 & 3.20n.s & 19.88 & 3.00 & 18.75 & 3.11 & 19.38 & $3.58 \mathrm{n} . \mathrm{s}$ \\
\hline Positive thinking & 20.33 & 2.00 & 19.00 & 3.57 & 19.67 & 4.09n.s & 17.88 & 3.52 & 19.63 & 3.54 & 21.13 & $2.90^{* *}$ \\
\hline \multicolumn{13}{|l|}{ Coping } \\
\hline Problem-focused Coping & 7.00 & 2.45 & 7.33 & 2.78 & 7.56 & 3.00n.s & 8.13 & 2.47 & 8.88 & 3.14 & 7.25 & $2.92 \mathrm{n} . \mathrm{s}$ \\
\hline Emotion-focused coping & 6.11 & 2.03 & 6.56 & 1.51 & 6.11 & 2.26n.s & 5.50 & 2.62 & 5.63 & 1.51 & 5.50 & $2.67 n . s$ \\
\hline Escape-avoidance coping & 7.78 & 4.15 & 10.11 & 3.26 & 9.56 & $4.00^{\#}$ & 7.63 & 4.84 & 9.75 & 3.54 & 9.63 & $2.92 \mathrm{n} . \mathrm{s}$ \\
\hline \multicolumn{13}{|l|}{ MBI } \\
\hline Emotional exhaustion & 16.44 & 3.40 & 17.11 & 3.48 & 15.44 & $2.55^{\#}$ & 19.88 & 3.48 & 18.50 & 3.78 & 15.88 & $2.70^{*}$ \\
\hline Depersonalization & 11.22 & 4.82 & 12.33 & 4.18 & 12.33 & $4.44 n . s$ & 15.38 & 6.59 & 13.13 & 3.80 & 14.75 & $3.28 \mathrm{n} . \mathrm{s}$ \\
\hline Personal accomplishment & 15.33 & 4.85 & 15.89 & 4.73 & 15.00 & 4.66n.s & 15.00 & 4.72 & 15.25 & 5.95 & 17.75 & $3.65 n . s$ \\
\hline \multicolumn{13}{|l|}{ Intention to leave the job } \\
\hline $\begin{array}{c}\text { Wants to quit } \\
\text { working as a nurse }\end{array}$ & 2.44 & 1.13 & 1.89 & 1.05 & 2.00 & $0.87^{\#}$ & 2.88 & 1.73 & 2.38 & 0.74 & 1.38 & $0.74^{*}$ \\
\hline $\begin{array}{l}\text { Wants to switch } \\
\text { hospitals or departments }\end{array}$ & 2.11 & 0.78 & 2.44 & 1.13 & 2.00 & $0.87 \mathrm{n} . \mathrm{s}$ & 3.38 & 1.30 & 3.00 & 1.41 & 2.50 & $1.07 \mathrm{n} . \mathrm{s}$ \\
\hline $\begin{array}{l}\text { Wants to continue } \\
\text { working as a nurse }\end{array}$ & 3.67 & 1.32 & 3.67 & 1.12 & 3.67 & $1.22 \mathrm{n} . \mathrm{s}$ & 3.25 & 1.49 & 3.75 & 1.28 & 4.00 & $1.31 \mathrm{n} . \mathrm{s}$ \\
\hline
\end{tabular}

rational belief immediately after intervention. In other words, "helplessness" was significantly higher in the group with high degree of irrational belief compared to the one with low degree after the completion of intervention. However, no significant difference was observed in 3 months after the completion of intervention. Moreover, the results of Frieldman test revealed that there was a significant difference in "helplessness" in the group with low degree of irrational belief $\left(\chi^{2}=7.56, p<0.05\right)$ and the group with high degree of irrational belief $\left(\chi^{2}=4.85, p<0.10\right)$. According to the result of multiple comparisons, significant differences were observed in "helplessness" between pretest and posttest $(p<0.01)$ and between posttest and follow-up $(p<0.10)$ in the group with low degree of irrational belief. On the other hand, in the group with high degree of irrational belief, significant differences were observed in "helplessness" between pretest and posttest $(p<0.10)$ and between pretest and follow-up $(p<0.05)$. That is, intervention was effective in reduction of "helplessness" in both groups, but the effect continued only in the group with high degree of irrational belief. Although there was no statistical significance, the total scores with irrational belief was lower than the baseline at posttest in "problem avoidance" and "dependence" in the group with high degree of irrational belief but was higher or the same as the baseline in the group with low degree of irrational belief.

With regard to automatic thoughts, the primary effect of "positive thinking" in the ATQ-R shorter form was significant $(p<0.01)$ in the group with irrational belief after intervention, and it was significantly higher in the group with high degree of irrational belief compared to the one with low degree after the completion of intervention. Moreover, 3 months after the completion of intervention, the primary effect was significant $(p<0.05)$ in the group, and it was significantly higher in the group with high degree of irrational belief compared to the low degree group. According to the results of Friedman test, a significant difference was observed only in "positive thinking" in the group with high degree of irrational belief $\left(\chi^{2}=12.62, p<0.01\right)$. Multiple comparisons revealed that there were significant differences between pretest and posttest $(p<0.05)$, post test and follow-up ( $p$ $<0.05$ ), and pretest and posttest $(p<0.05)$. Although no statistically significant difference was observed, the scores immediately after intervention were slightly lower than the baseline for both "negative evaluation of the future" and "self-blame" in the group with high degree of irrational belief, and those were also slightly lower 
than the baseline in 3 months after intervention. On the other hand, scores were slightly elevated in the group with low degree of irrational belief.

For coping, there was a significant difference in "problem avoidance/escape" in the group with low degree of irrational belief according to the results of Friedman test $\left(\chi^{2}=5.10, p<0.10\right)$. In addition, the results of multiple comparison revealed that there was a significant difference between pretest and posttest $(p<0.10)$. With coping, similar changes were observed in both groups with low/high degree of irrational belief; there was no significant difference observed between these groups. The scores increased in both groups immediately after intervention, but decreased slightly afterward. The improvement was sustained, however. That is, it seemed that coping brought the same effects in both groups.

b) Secondary endpoints: changes in burnout and Intention to leave the job in groups with high and low degrees of "irrational belief"

With regard to all subscales of burnout (MBI), no significant difference was observed after intervention, but the primary effect of "personal accomplishment" was significant in the group with MBI in 3 month after intervention $(p<0.01)$. That is, the effect was significantly higher in the group with high degree of irrational belief compared to the low degree group. According to the results of Friedman test, significant difference was observed in "emotional exhaustion" in the group with low degree of irrational belief $\left(\chi^{2}=5.24, p<0.10\right)$ and in the group with high degree $\left(\chi^{2}=6.66, p<0.05\right)$. The results of multiple comparison revealed that there was a significant difference between posttest and follow-up in the group with low degree of irrational belief $(p<0.05)$. On the other hand, a significant difference was observed between pretest and follow-up in the group with high degree of irrational belief $(p<0.05)$. In other words, improvement of "emotional exhaustion" was observed, but more interventional effects were observed in the group with high degree of irrational belief. Although no statistically significance was observed, "depersonalization” was reduced in the group with high degree of irrational belief.

With regard to the Intention to leave the job, no significant difference was observed after intervention, but primary effect of the Intention to leave the job "wants to continue working as a nurse" was significant in the group in 3 months after intervention $(p<0.05)$. That is, a significant decrease was observed in the group with high degree of irrational belief. According to the results of Friedman test, significant differences were observed in "wants to continue working as a nurse" in the group with low degree of irrational belief $\left(\chi^{2}=6.87, p<0.05\right)$ and in the group with high degree $\left(\chi^{2}=6.87, p<0.05\right)$. The results of multiple comparison revealed that there was a significant difference between pretest and post test in the group with low degree of irrational belief $(p<$ $0.10)$. On the other hand, significant differences were observed between pretest and follow-up $(p<0.05)$ and between posttest and follow-up $(p<0.05)$ in the group with high degree of irrational belief $(p<0.05)$. Although no statistically significant difference was observed, thoughts of "changing the hospital/department" were reduced in both groups; the thoughts of "continuing the nursing job" increased in the group with high degree of irrational thoughts.

\section{Discussion}

1) Study participation

180 nurses in their third year to participate in the study which received their consent for participation in the groupwork from 126 nurses were asked. The researchers themselves extracted the days when the nurses were on day-shift, and coordinated the groups. When conducting this study, trainings were held outside their day-time working hours without adjusting their work shifts. Therefore, it seemed that many nurses could not come due to their overtime work. The time frame of the sessions needs to be reconsidered in the future. At the same time, we should further verify the effectiveness of this program and encourage them to systemically incorporate the program into their workshops at the nursing department.

2) Effectiveness of cognitive behavioral therapy

By conducting this interventional program, irrational belief and negative automatic thoughts were reduced in the group with high degree of irrational belief. Then, burnout and intention to leave the job which were the consequences of irrational belief and negative automatic thoughts reduced. A partial improvement was observed in the group with low degree of irrational belief, but the change was not remarkable as had predicted. With regard to the items which showed nonstatistically significant differences, "helplessness" of irrational belief decreased and "positive thinking" of automatic thoughts increased in the group with high degree of irrational belief. With 
burnout, "emotional exhaustion” was reduced and "personal feeling of achievement” increased. As a result, the intention to leave the job "wants to quit working as a nurse" decreased significantly. This supports our hypothesis. Considering that burnout is deeply associated with irrational belief, it is shown that this program may be effective in nurses with irrational belief. This result supports the cognitive model suggested by Ohue et al. [14], which is represented as "stressor" => "irrational belief" => "automatic thoughts" => "burnout". It was also shown that the program developed this time could change "helplessness", an irrational belief, and encourage "positive automatic thoughts". Sheehy et al. [27] and Hori [28] indicated that the changes of irrational belief might not be easily sustained with a short term intervention. In this study, however, the effects continued for up to 3 months in participants with high degree of irrational belief. Hori has described that it is necessary to continue attempt to learn through workbooks so that the effect of reducing "irrational belief" will continue [28]. It seems that preparation of workbooks and daily reviews using a thought recording table as a part of homework reinforces behaviors and results in acquisition of behaviors. With regard to automatic thoughts, Ingram et al. has reported that positive automatic thoughts have negative correlation with depression or negative automatic thoughts [29]. In this study, it was also verified that positive automatic thoughts could reduce burnout or intention to leave the job. Moreover, a problem-solving technique which improves coping is incorporated in the direct relationship of "stressor" => "burnout". It was confirmed that "problem avoidance/escape" improved significantly in the group with low degree of irrational belief, and that they appeared improving in the group with high degree of irrational belief. There was no difference between the high degree group and the low degree group with other copings. On the other hand, with regard to the recognition modification, "helplessness" was reduced in the group with high degree of irrational belief. Considering that this significantly reduced intention to leave the job and burnout scores in this group, intervention on coping alone was not adequate in those with great cognitive distortion; hence, it was thought necessary to work on recognition modification. It was revealed that recognition distortion was associated with burnout, and was a buffering factor. Hence, approaches for both coping and recognition were needed.

3) Study limitations and future issues

One of the problems in this study is dropout of participants. With regard to the dropouts, it is unclear if there are many dropouts in the group with high degree of irrational belief simply because of the time issue or because of the problem avoidance behavior associated with high degree of irrational belief. Therefore, it is necessary in the future to coordinate the working hours with a help from the nursing department so that they will not struggle with time and to increase the number of participants as well. The results of this study only evaluate the change of each scale in 3 months after intervention. Therefore, it seems that continuance of the intervention effects has not been adequately studied. In the future, it is necessary to accumulate long-term follow-up data and demonstrate continuation of reduction of burnout or Intention to leave the job among nurses.

\section{References}

[1] Japanese Nursing Association Survey and Research Section Development and Promotion Department (2013) Investigation of the Actual Conditions of Rapid Turnover, etc., of Novice Nurses: Result (Bulletin) in 2012.

[2] Leiter, M.P. and Maslach, C. (2009) Nurse Turnover: The Mediating Role of Burnout. Journal of Nursing Management, 17, 331-339. http://dx.doi.org/10.1111/j.1365-2834.2009.01004.x

[3] Tsuchie, J. and Nakamura, Y. (1993) The Relationship between Nurses' Job Attitudes and "Their Stress or Burnout Syndrome”. Journal of Japanese Society of Nursing Research, 16, 9-19.

[4] Maslach, C. and Jackson, S.E. (1981) The Measurement of Experienced Burnout. Journal of Occupational Behaviour, 2, 99-113. http://dx.doi.org/10.1002/job.4030020205

[5] Spooner-Lane, R.S. and Patton, W.A. (2007) Determinants of Burnout among Public Hospital Nurses. Australian Journal of Advanced Nursing, 25, 8-16.

[6] Wu, S., Zhu, W., Wang, Z., Wang, M. and Lan, Y. (2007) Relationship between Burnout and Occupational Stress among Nurses in China. Journal of Advanced Nursing, 59, 233-239. http://dx.doi.org/10.1111/j.1365-2648.2007.04301.x

[7] Abual Rub, R.F. and Al-Zarus, I.M. (2008) Job Stress, Recognition, Job Performance and Intention to Stay at Work among Jordanian Hospital Nurses. Journal of Nursing Management, 16, $227-236$. http://dx.doi.org/10.1111/j.1365-2834.2007.00810.x

[8] Amagasa, T. (2000) Changes and Suicide in the Work Environment. Monthly Hodanren, 676, 24-29. 
[9] Beck, A.T. (1963) Thinking and Depression: Idiosyncratic Content and Cognitive Distortions. Archives of General Psychiatry, 9, 324-333. http://dx.doi.org/10.1001/archpsyc.1963.01720160014002

[10] Ellis, A. (1962) Reason and Emotion in Psychotherapy. Lule Stuart, New York.

[11] Beck, A.T. (1976) Cognitive Therapy and the Emotional Disorders. Meridian, New York.

[12] Kawamura, S. and Kokubun, Y. (1996) Investigation about Belief of an Elementary School Teacher. The Japanese Journal of Counseling Science, 29, 44-54.

[13] Ohue, T., Moriyama, M. and Nakaya, T. (2015) Development of the Irrational Belief Test for Nurses (IBTN): Examination of Reliability and Validity. Health, 7, 316-327. http://dx.doi.org/10.4236/health.2015.73036

[14] Ohue, T., Moriyama, M. and Nakaya, T. (2011) Examination of a Cognitive Model of Stress, Burnout, and Intention to Resign for Japanese Nurses. Japan Journal of Nursing Science, 8, 76-86. http://dx.doi.org/10.1111/j.1742-7924.2010.00161.x

[15] Wright, J.H., Michael, E., Thase, M.T. and Basco, M.R. (2006) Learning Cognitive-Behavior Therapy: An Illustrated Guide. American Psychiatric Publishing, Inc., Washington DC.

[16] Kubo, M. (2007) The Factorial and Construct Validity of the Japanese Burnout Scale. The Journal of Science of Labour, 83, 39-53.

[17] D’Zurilla, T.J. and Goldfried, M.R. (1971) Problem Solving and Behavior Modification. Journal of Abnormal Psychology, 78, 107-126. http://dx.doi.org/10.1037/h0031360

[18] Uehara, T. (2007) Skill up Psycho-Education. Seiwashoten, Tokyo.

[19] Sakano, Y. (1995) Cognitive Behavior Therapy. Nihonhyouronsha, Tokyo.

[20] Tao, M. and Kubo, M. (1996) Theory and Researches of Burnout. Seisinshobou, Tokyo.

[21] Tao, M. and Kubo, M. (1992) Measurement of Burnout. Psychology Review, 35, 361-376.

[22] Ohue, T., Moriyama, M. and Nakaya, T. (2012) Development of the Shorter Form of Japanese Version ATQ-R (Automatic Thoughts Questionnaire-Revised) for Nurses: Examination of Reliability and Validity. Journal of Health Sciences Hiroshima University, 11, 20-28.

[23] Kodama, M., Katayanagi, H., Shimada, H. and Sakano, Y. (1994) The Relationship among Stress Coping with Automatic Thoughts, State Anxiety, and Depressive Symptoms in College Students. The Human Sciences, 7, 14-26.

[24] Ozeki, Y. (1993) Refining the Stress Self-Rating Scale for University Students: Toward a Transactional Analysis. The Annual Report of the Graduate School of Comparative Studies of International Cultures and Societies, 1, 95-114.

[25] Sakata, N. (1989) A Study Concerning Psychological Stress: An Attempt to Prepare a Coping Scale (SCS). Educational Bulletin of Waseda University, 38, 61-72.

[26] Higashiguchi, K., Mori, H., Miura, K., et al. (1998) The Job Stressor of the Clinical Nurse-Considering the Psychological Characteristics and Measurement Scale Development Work Stressor. Health Psychology Research, 11, 64-72.

[27] Sheehy, R. and Horan, J.J. (2004) Effects of Stress Inoculation Training for 1st-Year Law Students. International Journal of Stress Management, 11, 41-55. http://dx.doi.org/10.1037/1072-5245.11.1.41

[28] Hori, M. (2007) Development of a Stress Management Program for University Students: Intervention for Cognitive Appraisal. Bulletin of the Graduate School of Education, Hiroshima University, 56, 284-292.

[29] Ingram, R.E., Kendall, P.C., Siegle, G., et al. (1995) Psychometric Properties of the Positive Automatic Thoughts Questionnaire. Psychological Assessment, 7, 495-507. http://dx.doi.org/10.1037/1040-3590.7.4.495 